\title{
Second Person Pronouns as Person Deixis in Bengali and English: Linguistic Forms and Pragmatic Functions
}

\author{
Md. Afaz Uddin ${ }^{1}$ \\ ${ }^{1}$ Assistant Professor, Department of English, Jahangirnagar University, Bangladesh \\ Correspondence: Md. Afaz Uddin, Assistant Professor, Department of English, Jahangirnagar University, \\ Bangladesh. E-mail: afazju@yahoo.com
}

Received: October 25, 2019

Accepted: December 20, 2019 Online Published: December 30, 2019

doi:10.5539/ijel.v10n1p345

URL: https://doi.org/10.5539/ijel.v10n1p345

\begin{abstract}
Second person pronouns functioning as person deixis are found to be used in both Bengali and English language to express the role relationships as well as the interpersonal relationships involved between the participants in conversation. However, the expression of these relationships through the use of second person deixis varies significantly in the two languages as it necessarily involves both linguistic as well as social aspects. Being an Asian language, Bengali has a detailed and somewhat complex system of encoding the role relationship of the participants, their interrelationships, their social status, level of formality and politeness involved, and so on by the use of second person deixis. In contrast, English, a European language, exhibits relatively simple and straight forward ways of encoding the aforementioned issues of conversation. Based on the intuitive observation of the utterances of the two languages, the present study intends to make a comparative analysis of the use of second person deixis in Bengali and English with a view to exploring the extent to which the two languages differ linguistically and pragmatically in their encoding of social information with the use of such deictic expressions.
\end{abstract}

Keywords: deixis, deictic expression, interlocutor, intuitive observation, formality, politeness

\section{Introduction}

Deictic expressions (i.e., this, that, she, he, here, there, now, then, etc.) are found to be present in almost all known human languages on the planet (Huang, 2014). A set of personal pronouns (e.g., he, she, you, etc.) function as one of the basic ways of expressing person deixis in many languages of the world. However, there are variations among languages in terms of their having a range of linguistic forms and pragmatic functions. In other words, languages differ in the ways they encode the role relationship of the participants, their social status, level of formality and politeness, and so on by the use of personal pronouns. Heine and Song (2011, pp. 587-630) state that person deixis is perhaps the most diversified and complex in societies characterized by pronounced forms of hierarchical social organization and status, and hence, distinctions in personal reference and address are likely to thrive in such societies. The person deixis in Bengali and English are deeply rooted in different cultural backgrounds and may be endowed with different cultural connotations. The person deixis in Bengali (an Indo-European language) is grammaticalized through the pronominal system. However, it has got a rich array of morphological options functioning as person deixis. The person deixis is contained with a number of pragmatic meanings in addition to their basic semantic connotations. The second person pronoun functioning as person deixis is a prime example of that case. Unlike English where the pronominal pattern allows a restricted set of second person pronoun devoid of any social and contextual information, the pronominal system in Bengali exhibits a range of morphological options which give rise to different set of socially determined meanings to the pronouns functioning as deictics. Consequently, in addition to their being person deixis only, they are social deixis and instances of honorifics too. Bernard Spolsky (1998) states that "the choice of second-person pronoun and the related phenomenon of terms of address in Western European languages in particular shows the formalization of politeness and status in a language." Spolsky further suggests that the second-person pronouns connote the speaker's social positioning, as understood by themselves, and the degree of social respect the speaker confers upon the addressee. In this paper, I intend to make a comparative analysis of the range of second person pronouns used in Bengali and English for encoding the person deixis with a view to exploring the extent to which the two languages differ linguistically and pragmatically in their encoding of social information with the use of such deictic expressions. The paper also examines how the two languages differ in terms of their 
encoding of honorification by the use of the second person deixis. The primary data for the analysis of the second person pronouns functioning as deictics in the two languages comes from the intuitive observation of the utterances of the two languages, which helps to form the research questions as of 'how do the two languages differ, linguistically and pragmatically, in their use of second person pronouns for encoding person deixis?' and 'what pragmatic functions do the second person pronouns carry out in the two languages?'.

\section{Theoretical Overview}

A discussion on the comparison of personal pronouns functioning as deictics in the two languages demands at least a minimum of introduction to some basic concepts and terminologies found in the field of deixis. What follows then is a brief discussion of some basic concepts related to the subject matter of the paper.

\subsection{Deixis}

Generally speaking, 'deixis' refers to the phenomenon in which meanings of some words and expressions in an utterance are understood in terms of the contextual information. 'Deixis' is a technical term derived from the Greek word meaning "pointing or indicating through language" (Yule, 1996, p. 9). Huang (2014, p. 169) remarks that 'deixis' is directly concerned with the relationship between the structure of a language and the context in which the language is used. It is the phenomenon whereby features of context of utterance are encoded by lexical and/or grammatical means in a language. Huang also argues that 'deixis' is a universal linguistic phenomenon, that is, all human languages contain deictic expressions. Deixis is like reference by means of an expression whose interpretation is relative to the usually extra linguistic context of the utterances, such as who is speaking, the time and place of speaking, the gesture of the speaker, or the current location in the discourse (Lyons, 1981, p. 170). To have more understanding about deixis, it is necessary to be familiar with the types of deixis itself. Deictic expressions, which are sometime referred to as indexicals, are classified into four major categories such as person deixis, place deixis, time deixis and social deixis by Levinson (1983).

\subsubsection{Person Deixis}

According to Levinson (1983, p. 62), "person deixis concerns the encoding of the role of participants in the speech event in which the utterance in question is delivered". Huang $(2014$, p. 174) states that 'person deixis' is concerned with the identification of the interlocutors or participant-roles in a speech event. In a speech situation, there is a speaker and at least one addressee, and these may be referred to through different grammatical and lexical devices in a given language. The speaker and addressee continuously switch roles as the conversation unfolds. This continuous change can have certain interesting linguistic consequences: when the roles switch, the terms used to refer to the two interlocutors switch with them. Whenever the interlocutors change discourse roles, the whole system of deictic coordinates changes, since the linguistic forms follow the roles rather than the people. This change of coordinates introduces a sort of relativity into the discourse that is a defining feature of deixis. Person deixis clearly operates on a basic three part divisions, exemplified by the pronouns for first person (I), second person (you) and third person (he, she, or it).

\subsubsection{Place or Spatial Deixis}

Spatial or place Deixis refers to how languages show the relationship between space and the location of the participants in a discourse. Fromkin, Rodman, and Hyams (2003, p. 218) said that, the expression of place deixis requires contextual information of the place of the utterance such as here, there, this, place, that, place, this city, etc. In English, the distinction between space and the location of the participants in a discourse is shown in demonstrative pronouns (that-this), or in adverbs (here-there), directional terms (before-behind, left-right, front-back) or in phrases such as at our place, your left, etc.

\subsubsection{Time or Temporal Deixis}

Time or temporal deixis is an expression in relation to the certain point of time when the utterance is produced by the speaker. According to Levinson (1983, p. 62), time or temporal deixis is a reference to the time relative to a temporal reference point which is the moment of the utterance (spoken or written inscribed).

\subsubsection{Social Deixis}

According to Levinson (1983, p. 63) 'social deixis' concerns the encoding of social distinctions that are relative to participant-roles, particular aspects of the social relationship holding between speaker and addressee(s) or speaker and some referent. Huang (2014, p. 208) states that 'social deixis' is concerned with the codification of the social status of the speaker, the addressee, or a third person or entity referred to as well as the social relationships holding between them. The information encoded in 'social deixis' may include social class, kin relationship, age, sex, profession, ethnic group, and so on. Thus, social deixis is closely associated with person 
deixis. In analyzing social deixis, we need to realize that social deixis truly cannot be separated from the concept of honorifics which means that it concerns about the relative rank or respect between speaker, referent, and bystander (Levinson, 1983, p. 90). Levinson (1983) further points out that the social deixis is concerned with the grammaticalization of social information. He singles out social deixis as a separate type covering $[\ldots]$ those aspects of language structure that encode the social identities of participants, or the social relationship between them, or between one of them and persons and entities referred to. There are of course many aspects of language usage that depend on these relations [...], but these usages are only relevant to the topic of social deixis in so far as they are grammaticalized.

\subsection{Honorifics}

Honorifics refer to the "direct grammatical encodings of relative social status between participants, or between participants and persons or things referred to in the communicative event" (Brown \& Levinson, 1987, p. 276). According to Irgens (2017), in contrast to person deixis, honorifics focus on respect, deference and relationships rather than exclusively on discourse participant roles. By the appropriate use of honorifics, one is able to label a referent or to identify oneself with a certain social standing.

\section{Review of Literature}

Foley (1997) talks about numerous Asian languages. These languages have an elaborate system of honorifics, "grammatical morphemes and special classes of words indicating social deixis among the interlocutors or the referent of a participant in the utterance" (p. 319). Foley further remarks that there are some expressions that are not understood unless the interlocutors have some knowledge about the context of the utterance, knowledge about the status of those involved, the intend of the speaker, the place and time of the utterance.

Heine and Song (2011) observes that in some societies, distinctions in personal reference and address are likely to thrive, paradigm cases of which could be found particularly in Southeast and East Asia. Languages such as Thai, Burmese, Khmer, Vietnamese, Korean, and Japanese dispose of complex systems of personal pronouns based on distinctions of honorification. The Thai second person marker 'tua', for example, which literally means 'body, self', is (i) an affectionate or intimate term, used for speaking to equal or to inferior not older than the speaker, and (ii) used by a child or young woman speaking to an intimate (sibling, friend, fiance', husband) in anger, expressing a sense of injury, and implying a disavowal or impersonalization of the close relationship.

Bilá et al. (2017) states that the present-day English is the only mainstream language with the absence of morphological markers for conveying T/V relationships, i.e., the verb is not marked for this purpose. In other words, a lexeme (i.e., pronouns corresponding to French tous and vous) and an inflectional morpheme do not reside in the inventory of the language to serve that purpose. This inevitably implies that in English the conceptualization of social deixis may as well be different. Due to the absence of overt (explicit) markers of T/V distinction, it can be presupposed that English speakers rely on markers embedded in mind; logical inference is that markers of $\mathrm{T} / \mathrm{V}$ distinction are present, yet in the form of non-conscious utilization of categorial aspects of intonation.

Irgens (2017) has made a contrastive analysis of person deixis in English and Japanese. He argues that the person deixis in English is grammaticalized through the pronominal system and verbal agreement inflection. In Japanese, in contrast, person deixis is primarily lexically manifested in the form of "person nouns", whose meanings vary according to different social variables. He further points to the fact that Japanese allows for widespread nominal ellipsis, so that such person nouns are frequently left unexpressed in real discourse. These features lead the researcher to form the hypothesis that person deixis is less grammaticalized in Japanese than in English. In other words, Japanese is less person-prominent than English. However, this finding does of course not imply a radical position that person deixis is not manifested at all, only that it is less grammaticalized and therefore more lexicalized.

\section{Comparative Analysis}

There exist differences between Bengali and English language as regard to the grammatical forms and pragmatic functions of the second person pronouns functioning as deixis. Bengali language possesses overt pronominal and morphological means of personal and social deixis, whereas the English language lacks such overt means of expressing social deixis. English has only one second person pronoun form 'you' for both singular and plural, and nominative and objective case, which realizes the role of the second person participant(s) or the addressee(s) in the real life conversation and the verb that agrees with it is not morphologically marked (Bilá et al., 2017, pp. 80-93).There is no inflected, derived or lexically expanded forms of 'you' in English to represent the pragmatic functions of the second person deixis which results in the neutralization of the second person pronoun in 
conversation. Bengali, on the other hand, has three separate morphemes for singular nominative pronouns of address-apni, tumi, tui. These the forms have their corresponding singular objective and singular possessive forms as well as plural nominative, plural objective and plural possessive forms. All these plural forms, however, are derived from the basic singular pronouns of address with the process of suffixation. In other words, Bengali language allows for a set of grammatical morphemes as forms of second person address, the grammatical and pragmatic functions of which are extended in process of suffixation. Furthermore, the verbs that concord with those pronouns contain a special inflectional morpheme. In practice, this means that Bengali refers to the second person addressee(s) in a more specific way than English, identifying the referent in terms of number and case in addition to the participant(s) role in the conversation and other relevant extralinguistic, social information. The table below and the examples that follow illustrate how the two languages differ in terms of their use of the second person pronouns of address.

Table 1. How the two languages differ in terms of their use of the second person pronouns of address

\begin{tabular}{llllll}
\hline Case & Number & Formal/polite/hierarchical & Familiar/polite/intimate & intimate/impolite/neglecting & English \\
\hline Nominative & Sing. & আभনি (apni) & তুমি (tumi) & তু (tui) & you \\
& Plur. & আभনারা (apnara) & তোমরা (tomra) & তোরা (tora) & you \\
Objective & Sing. & আभনাকে (apnake) & তোমাকে (tomake) & তোকে (toke) & you \\
& Plur. & আभনাদেরকে (apnaderke) & তোমাদেরকে (tomaderke) & তোদেরকে (toderke) & you \\
\multirow{2}{*}{ Possessive } & Sing. & আপনার (apnar) & তোমার (tomar) & তোর (tor) & your \\
& Plur. & আभনাদের (apnader) & তোমাদের (tomader) & তোদের (toder) & yours \\
\hline
\end{tabular}

Note. Hanne-Ruth, 2010, 123f.

\section{I আभনি/আপনারা স সঠিক সিদ্ধান্ত নিয়েছেন।}

(apni/apnara shotik shiddhanto niechen)

You right decision have taken.

You have taken the right decision.

II তুমি/তোমরা সঠিক সিদ্ধান্ত নিয়েছ।

(tumi/tomra shotik shiddhanto niecho)

You right decision have taken.

You have taken the right decision.

III তুই/তোরা সঠিক সিদ্ধান্ত নিয়েছিস।

(tui/tora shotik shiddhanto niechish)

You right decision have taken.

You have taken the right decision.

In Bengali, the second person singular pronouns of address in the nominative case have three different morphemes which are used to addressees of different social standings. They also make different types of agreement with the verb forms having particular inflections. Hanne-Ruth $(2010$, p. 125) states that "there are three degrees of politeness for the 2nd person addressee: familiar, polite and intimate". In example (1) above, the pronoun 'apni' in singular and 'apnara' in plural refers to person(s) who are in formal and polite relationship with the speaker. As a result, the verb has a particular morphological inflection indicating politeness distinct from the examples (2) and (3) as they are relatively less formal and less polite. These pronouns have semantic meanings, i.e., an addressee or addressees in a conversation. However, apart from their purely semantic content, they convey a good amount of socially determined information about the participants of the conversation such as their relationship, social status of the addressee(s), scale of politeness and formality, and social distance or proximity involved. With these forms, the speaker also expresses respect and deference towards the addressee(s). In other words, they indicate the hierarchical relationship existing between the speaker and the addressee(s) who are operating on a high level of formality and politeness, hence, are in distant social relationship. According to (Hanne-Ruth, 2010, p. 125) the second person polite 'apni' is the usual form of address between strangers, non-acquaintances, work colleagues, to aged people, and anyone outside the immediate circle of friends and family, but also for particularly respected members of the family and society. Therefore, the formal and polite 'apni' can be placed in the ' $\mathrm{V}$ ' axis of the $\mathrm{T} / \mathrm{V}$ distinction. Among strangers, the transition from a $\mathrm{V}$-form to a 
T-form is a sign of a closer friendship, the expression of rapport or of a more relaxed relationship; in the case of work associates, the same might be applicable, yet with the necessary streak of superiority when talking business. The English counterpart 'you', on the other hand, does not indicate any such social information, and hence a neutralized deictic expression.

In example (2), the second person singular pronoun 'tumi' and plural 'tomra' in the nominative are also distinct morphological forms, making special agreement with the verb having a particular inflection too. Semantically, they also refer to an addressee in a conversation. In addition, however, they may point to particular person(s) who are in a familiar, friendly and intimate social relationship with the speaker. However, although the degree of formality and politeness between the interlocutors is quite reduced with the use of such pronouns compared to those in the example (1), the speaker and addressee(s) still stand in a respectable social relationship and tend to be aware of the 'public self-image' of each other. The form may also connote to an intimacy of certain emotional and/or genealogical bonding between the interlocutors. That is, in addition to their purely semantic content, the pronouns contain a lot of social information. In English language, however, such information cannot be obtained from the neutralized second person pronoun 'you'.

A morphological form, the singular 'tui' and plural 'tora' in the example (3) above are also second person pronouns in Bengali language. The semantic meaning of the forms as usual refer to addressee(s) in the conversation. However, the morphemes indicate particular addressee(s) who are in a friendly, jovial, informal or even hostile relationship with the speaker. This form of address may be put under the category of $\mathrm{T}$-axis of the $\mathrm{T} / \mathrm{V}$ dichotomy. Among the three forms of indicating addressee(s) in conversation, these form are most flexible in the sense that their use can vary depending on a number of situational variables (Wenger, 1906, p. 51). Generally, the forms are very commonly found among younger people talking with their friends and people of 'lower social status' working in the same profession. In addition, the forms are also used by the elderly people in a familiy situation to address the younger members of the family. They are also very commonly used when people are angry or hostile towards the addressee(s). Other encounters when the expression 'tui' is used are child-to-child, teenager-to-teenager, or the elderly-to-children/teenagers' conversations. Sometimes, people of higher soci-economic status use these forms to address people of lower soci-economic status, usually with the purpose of looking down upon the addressees' social belonging. This form of address may confuse a non-native speaker as it has multiple layer of meaning which are dependent on specific context of use. In English language, it is again the morpheme 'you' to replace the Bengali forms, which is completely unable to provide the varied set of social information conveyed by the Bengali counterparts.

\section{Discussion}

Bengali language has an elaborate system of second person pronouns which function as person deixis expressing relative rank and deference between speaker and addressee, level of politeness and formality, social distance or proximity, and so on. In addition, these second person pronouns along with their agreements with the distinct verbal inflections indicate social deixis among the interlocutors or the referent of a participant in the utterances, as Lyons (1977) identifies social deixis as the linguistic coding of social roles and status of the participants, and "the grammaticalization of social information" (Levinson, 1983, p. 89). Moreover, among the three forms of the second person pronouns of address, 'apni' in singular and 'apnara' in plural, are the most polite, formal, social rank and deference expressing forms. Consequently, they are true instance of referent honorifics encoded in separate classes of grammatical morphemes, as referent honorifics are forms that "are employed by the speaker to show respect towards the referent" (Huang, 2014, p. 209). Anderson (1920, p. 14) states that in "Bengali language, 'apni' (yourself, your honour), and 'apnara' (plural) are the honorific methods of addressing a second person like the Spanish 'Usted'". Therefore, the Bengali forms of addressing a second person in conversation i.e., apni, tumi, tui refer to the illocutionary addressees with plenty of additional information about them. English you is a deictic term because it refers to the locutionary addressee(s) without conveying any additional information about them (Lyons, 1996, p. 307).

A number of European languages have a familiar tu/vous type of distinction in second-person singular pronouns expressing a number of socially deictic effects. The distinction has been known as the T/V distinction. In a T/V system, there are two second-person singular pronouns: one familiar or $\mathrm{T}$, and the other polite or $\mathrm{V}$. The system of encoding social deixis through the second person pronouns in Bengali is to some extent similar to the well-established T/V dichotomy, but not exactly the same. Unlike the T/V dichotomy, it has a tripartite form of second person pronouns ('apni/tumi/tui') conveying more specific social information than the $T / V$ languages. That is, in practice Bengali has three singular second person pronouns of address. While the formal and polite 'apni' can be placed in the ' $\mathrm{V}$ ' axis and 'tui' in the ' $\mathrm{T}$ ' axis of the $\mathrm{T} / \mathrm{V}$ distinction, the semi-formal, emotionally intimate form 'tumi' does not fall into any of these categories. Helmbrecht (2003, cited in Huang, 2014) 
considers this third form as neutral form (N). Therefore, Bengali can be considered as a T/N/V language in its use of second-person singular pronouns of address. English, on the other hand, does not fall under the category of either T/V or T/N/V languages. Although most European languages (such as Slavic languages, Romance languages, Germanic languages) exhibit $\mathrm{T} / \mathrm{V}$ dichotomy in expressing social deixis, English is the only mainstream European language with the absence of such dichotomous second person deixis for addressing the interlocutors in the conversations. Ardila (2003, p. 79) argues that English language, however, has developed a number of formulae to establish a distinction between the second-person pronoun in informal situations and in formal situations, i.e., 'you' or 'you, [e.g.,] John' versus 'you, sir' or 'you, [e.g.,] Mr. Smith' respectively. Therefore, whilst 'you' may be considered deictic, it can also be regarded as non-deictic depending on whether it is accompanied by a first name, a 'Mr', or a 'sir', for it then conveys additional information about the relation between speaker and addressee imposed by the situation. Bila et al. (2017) argues that the conceptualization of social deixis is different English, i.e., English speakers rely on markers of additional social information "embedded in mind in the form of non-conscious utilization of categorial aspects of intonation (pp. 80-93)".

\section{Conclusion}

Personal pronouns are used in many of the world languages to express person diexis conveying various kinds of socially determined information about the participants in a speech event. The second person pronouns in Bengali language consist of a particular set of morphemes which function as person deixis. These pronouns, apart from their mere semantic meanings, express information regarding the relationship between the participants, social status of the addressee, formality of the conversation, respect and politeness toward the addressee, and so on. As a result, they are social deixis and examples of honorifics as well. This being the case, Bengali language has a very detailed and complex pattern of pronominal system for encoding person deixis which in extension function as markers of social information. English, on the other hand, has a limited deictic option devoid of such functions. English you is used to addresses of all kinds irrespective of the features of the communication situations. Therefore, the linguistic form you of the English language does not perform the function of social deixis and honorifics as such.

\section{References}

Anderson, J. D. (1920). A Manual of the Bengali Language. Cambridge: Cambridge University Press.

Ardila, J. A. G. (2003). (Non-Deictic, Socio-Expressive) T-/V-Pronoun Distinction in Spanish/English Formal Locutionary Acts. Forum for Modern Language Studies, 39(1), 74-86. https://doi.org/10.1093/fmls/39.1.74

Bilá, M., Kačmárová, A., \& Kraviarová, M. (2017). Expressing Social Deixis through Prosody: A Case Study of American English. Journal of Theoretical Linguistics, 15(1), 80-93. Retrieved January 10, 2019, from http://www.skase.sk/Volumes/JTL36/pdf_doc/04.pdf

Brown, P., \& Levinson, S. C. (1987). Politeness: Some Universals in Language Usage. Cambridge: Cambridge University Press. https://doi.org/10.1017/CBO9780511813085

Foley, W. A. (1997). Anthropological Linguistics: An Introduction. Oxford: Basil Blackwell.

Fromkin, V., Rodman, R., \& Hyams, N. (2003). An Introduction to Language. Massachusetts: Heinle.

Hanne-Ruth, T. (2010). Bengali: A Comprehensive Grammar. London and New York: Routledge.

Heine, B., \& Song, K. A. (2011). On the Grammaticalization of Personal Pronouns. Journal of Linguistics, 47(3), 587-630. https://doi.org/10.1017/S0022226711000016

Helmbrecht, J. (2003). Politeness Distinctions in Second Person Pronouns. In Y. Huang (Ed.), Pragmatics. Oxford: Oxford University Press.

Huang, Y. (2014). Pragmatics. Oxford: Oxford University Press. https://doi.org/10.1075/pbns.112.10hel

Irgens, B. M. (2017). Person Deixis in Japanese and English: A Contrastive Functional Analysis. Unpublic PhD Research, University of Bergen: AIT Bjerch AS.

Levinson, S. C. (1983). Pragmatics. Cambridge: Cambridge University Press.

Lyons, J. (1981). Language and Linguistics. Cambridge: Cambridge University Press.

Lyons, J. (1996). Linguistic Semantics: An Introduction (p. 307). Cambridge: Cambridge University Press.

Spolsky, B. (1998). Sociolinguistics. Oxford: Oxford University Press.

Wenger. M. (1906). Bengali Grammar (Ed. G. H. Rouse). Calcutta: Baptist Mission Press.

Yule, G. (1996). Pragmatics. Oxford: Oxford University Press. 


\section{Copyrights}

Copyright for this article is retained by the author, with first publication rights granted to the journal.

This is an open-access article distributed under the terms and conditions of the Creative Commons Attribution license (http://creativecommons.org/licenses/by/4.0/). 